\title{
Sustainable Consumerism via Context-Aware Shopping
}

\author{
Johannes Klinglmayr, Linz Center of Mechatronics GmbH, Linz, Austria \\ Bernhard Bergmair, Linz Center of Mechatronics GmbH, Linz, Austria \\ Maria Anneliese Klaffenböck, Linz Center of Mechatronics GmbH, Linz, Austria \\ LeanderB. Hörmann, Linz Center of Mechatronics GmbH, Linz, Austria \\ Evangelos Pournaras, ETH Zurich, Zürich, Switzerland
}

\begin{abstract}
We are living in a world of vast information. The means of the Internet allow access to diverse sources of information, with social media and Internet of Things technologies significantly expanding the informational ecosystem. With the use of social media, it is easy for 'like-minded' people to group up and initiate movements. One way to articulate such movements is via political consumerism. Users group together and boycott or buycott (boost purchases) for certain products with a concrete collective goal in mind. If, however, the collective goal is vague and abstract, as in the case of sustainability, this bottom-up strategy may lose its popularity and attraction. In this paper, we introduce a new concept of how individual consumers can follow their own understanding of sustainability, while at the same time benefiting from collective and participatory actions. We discuss how the means of ICT can be used to develop political consumerism further to transform individual policies into collective statements.
\end{abstract}

\section{KEYWORDS}

Data Analysis, Self-Regulation, Social Self-Organization, Techno-Socio-Economic System

\section{INTRODUCTION}

We are living in a world of vast piles of information. The means of the Internet allow access to diverse sources of information, with social media and Internet of Things technologies significantly expanding the informational ecosystem. This new era comes with various implications by the systematic datadriven approaches that are applied in several techno-socio-economic systems. Take for instance predictions for stock markets, or obtaining pictures on user groups and even individual user behavior. At the individual level, users can design their news environment and select news boards, feeds, and blogs. They can capture their interest on almost any topic, create specific forums and build up networks of similar interests. At a collective level, these individual users create political movements, new trends and social phenomena.

A prime example for the power of self-organization in a social context is political consumerism. People of similar political view boycott or boost purchases of specific products in order to make a 
statement (Stolle et al., 2005). These initiatives may appear spontaneously, they are "citizen prompted, citizen-created action involving people taking charge of matters that they themselves deem important in a variety of arenas" (Micheletti, 2003). These initiatives are "bottom-up grassroots engagement rather than mobilization within rigid organizational structures." (Balsiger, 2013). The combination the political concerns with market actions is often also based on ethical considerations and referred to as political consumerism (Micheletti et al., 2003). Political consumerism has happened since decades. Its arising, however, is still considered to be spontaneous, despite the fact that social media can be subject of manipulation and propaganda (Ferrara, 2015; Gunitsky, 2015). In the past, boycotts were predominantly directed against companies, countries or policies of a country (Stolle et al., 2005).

The political consumerism presents two facets of self-regulation. First, the consumption is selfregulating as it is an element within the understanding of supply and demand in market economy (Witt, 1997). Second, consumers regulate themselves in regard to their collective political view. If this collective view has a compact and clear perspective, consumers can deduce their own purchasing rules rather easily. If, however, the collective view is vague, deductions might vary, and so will the actions of the individual consumers. In this situation, no feeling of community is created and the collective motion is less likely to be effective.

In this paper, we elaborate on a new concept introduced in an earlier work (Klinglmayr et al., 2016), which develops the method of political consumerism further. It allows the creation of a community feeling for a topic that is by definition vague and imprecise, the sustainable consumerism ${ }^{1}$. We elevate political consumerism to an ICT-enabled techno-socio-economic system. We use data mining and data analysis techniques to aggregate the piles of product information and present it to the user in an understandable and simple format. Together with hardware installments and a smart phone application, we develop a new consumer-centric platform. Our novel concept allows the individuals to (i) follow a personalized and conscious understanding of sustainable consumerism, (ii) find 'likeminded' people within aware consumers and (iii) reach out to retailers with their concerns and create awareness amongst people outside a movement.

To achieve this level of self-regulation among consumers, we design and develop a platform with a decision support engine and a communication unit. On the individual level, we empower consumers by condensing the piles of information on products to comprehensive data, relating these data to the user's privacy-preserved preferences and show consumers the social binding and collective purchasing power they create by following the concept. On a collective level, we study how this empowerment changes the way consumers purchase. Within future field tests on the supermarket shop floors, we will observe the collective consumption behavior over months. We will analyze how consumption patterns change and if they reflect the intrinsic motivation of consumers in regard to the environment and sustainability at large.

This paper extends earlier work (Klinglmayr et al., 2016) with the following contributions. A specific focus is put on the localization functionality of the proposed tool. This includes a review of existing technologies as well as evaluation measurements of localization systems. Also, the related work section was expanded including additional academic references.

This paper is organized as follows: Section "Consumer Behavior Patterns" addresses needs and concepts for sustainable consumption. Section "Towards a Self-Regulatory Consumer System" presents a new self-regulation framework for sustainable consumers. Section "Smart Phone Localization" gives an overview about different possibilities regarding indoor smart phone localization and addresses the technology of choice, underpinned by measurement results. Finally, we summarize the paper and give an outlook on next steps. 


\section{CONSUMER BEHAVIOR PATTERNS}

We develop a new concept and platform for political consumerism regarding sustainable consumption. Political consumerism is a very broad concept. For our pilot implementation, we focus on the consumerism within the supermarket and address food products. If the findings and platform results are promising, we intend to generalize the approach to other products and sectors. We justify the demand for this concept on the following observations in society.

\section{Consumer Trends in Society}

The willingness among consumers to address environmental concerns with their purchases is given. Roughly one third of all consumers participating in a representative poll indicate that the products impact onto the environment is significant to them (TNS Political \& Social, 2013). The same poll also shows that the impact on the environment is not the only important aspect for consumers. The quality of a product and its price are even more important. Still, environmental concerns do play a role.

While the political conviction to address environmental concerns via purchases is present, a significant number of consumers cannot estimate the impact of a product. More than $40 \%$ of all consumers participating in representative polls indicate that they know little about the environmental impact of the product they buy and use. Governments and institutions are addressing this issue and have introduced a significant amount of product labels. Nevertheless, more than $50 \%$ of all consumers participating in representative poll indicate the labels are unclear, and for $91 \%$ of consumers, the information is unclear for some products (TNS Political \& Social, 2013). This lack of knowledge regarding labels is not restricted to environmental concerns. For instance, recognition and knowledge of the correct meaning of four common public information logos among European consumers is strikingly low. Only $3 \%$ of consumers recognized and understood all four (European Commission, 2011). Even though general and common labels are often little understood, the number of additional labeling schemes available is large. For instance, Spain has around 180 different labeling schemes (Ipsos and London Economics Consortium, 2013). This hints to the level of confusion among consumers. Still, consumer experiments show that up to $90 \%$ of all consumers choose products with labels if the price is equal to unlabeled products (TNS Political \& Social, 2013).

\section{The Potential for Self-Regulatory Sustainable Consumption}

Sustainable consumption is described by OECD as follows: "The use of services and related products, which respond to basic needs and bring a better quality of life while minimizing the use of natural resources and toxic materials as well as the emissions of waste and pollutants over the life-cycle of the service or product so as not to jeopardize the needs of future generations" (Organisation for Economic Co-operation and Development, 2001).

This statement suggests that consequences of our actions are disputable and no objective collective understanding of sustainable consumption can be given. The context of the "future generation" for example does not indicate if it refers to a world-wide aspect or a country-wide aspect, which comes apparent if one refers to standards of living in developed or less developed countries. For every individual, the notion of and motivation for sustainable consumption may be different and no collective overall understanding might be found. On the contrary, certain actions of individuals might fit together, even though their understanding of sustainable consumption differs.

These subjective notions of sustainable consumption indicate why current forms of political consumerism are inadequate. The underlying principle of political consumerism is the collective agreement to one single policy. Especially when addressing sustainable consumerism, this single policy is hard to find, if ever existing. The ambiguity of motivation is for example also apparent regarding ethical consumption, e.g. (Grauel, 2016), or regarding organic products in (Andersen, 2011).

However, one of the main actors for sustainable consumption is the individual consumer, which is for example studied in (Ghvanidze et al., 2016; Adams \& Raisborough, 2010; Andorfer \& Liebe, 
2013). Integrating sustainable consumption into everyday behavior patterns is one of the key topics for governments aiming at long term sustainability.

A promising way towards sustainable consumption is the theory of "ecological citizenship" (Dobson, 2003), which is also supported empirically (Seyfang, 2006). An ecological citizen feels responsible for the environment, and takes action in private and public affairs. She or he avoids unfair actions, for example, by considering effects onto common goods in the everyday purchases and modifying consumption patterns if necessary. The environmental footprint initiatives, e.g. (World Wide Fund for Nature, 2016), give a good example of how such considerations can be made. The footprint visualizes how many earths it would need if everybody followed a given lifestyle. The voluntary purchasing decision with the aim of sustainable consumption is hence a paradigmatic example of self-regulation in society.

An example of ecological citizenship is given by the empirical study of (Seyfang, 2006): A local organic network, named Eostre Organics (EO), was studied. EO provided a local market for organic products and specifically includes small producers. Consumer could go to the market, interact with the producers, and get local and organic products on a narrow variety as in the supermarket. EO also offered educational farm visits. Survey results indicate that $75 \%$ of respondents shopped at EO because they considered organic food as safer, more nutritious, tastier, or better to eat. $70.5 \%$ of respondents shopped at EO because of environmental protection reasons. $65.2 \%$ of respondents shopped at EO because of a desire to support the local economy and community. Within the study, the author concludes that consumers could trust the product qualities through the interactions with the producers. Consumers considered other consumers as part of their community. Overall food was considered a mechanism for community-building, consumers considered their everyday consumption decision as being deeply political. Finally, EO has an influence on developing informed, educated communities around food through education, outreach, literature, farm visits and web sites. According to the authors, these findings have implications on establishing an "alternative sustainable consumption through a personal commitment to global environmental and social justice."

\section{TOWARDS A SELF-REGULATORY CONSUMER SYSTEM}

This section introduces a self-regulation framework for sustainable consumers. It also introduces the technical concept behind the framework realization and discusses its implications on the social dynamics between the involved actors.

\section{Framework}

Individual consumers are the central entities in the socio-economic system of political consumerism. From the perspective of self-organization, we can interpret the sustainable consumerism as the emerging property originated from the actions of the local system entities, the consumers. To encourage the emergence of sustainable consumerism, we address the action of the local entities. As these entities are humans, our approach is to address the intrinsic motivation of each individual.

We provide the capability to the consumer to purchase according to his/her own belief and empower him/her to become an aware and critical customer, compare (Gjerris et al., 2016). As addressed above, consumers can then take product aspects, such as environmental concerns, into consideration. We also increase the consciousness among aware consumers regarding their purchasing power and the community of 'like-minded' consumers, see Figure 1 for illustration.

From a technical perspective, we develop an ICT-enabled platform, which uses data mining and data analysis techniques together with hardware installments and a smart phone application.

\section{Technical Concept}

In order to perform the self-regulated decisions, users need to obtain condensed product information that focuses on the user preferences. 
Figure 1. Strategies for collective consumerism: a) Classical political consumerism - Consumers collectively follow one prescribed policy when shopping; b) Consumers follow their own policy. The understanding of a political movement comes with the feedback of the ASSET pilot platform (Klinglmayr, 2016).

a)

\section{Political Consumerism}

one policy fits all
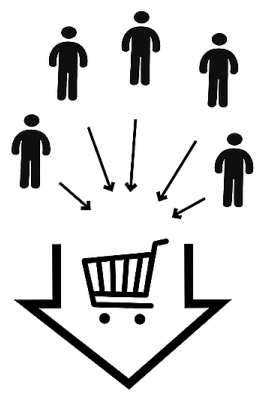

sustainable consumerism b)

\section{ASSET Consumerism}

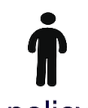

policy

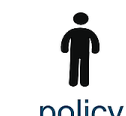

multiply

policy

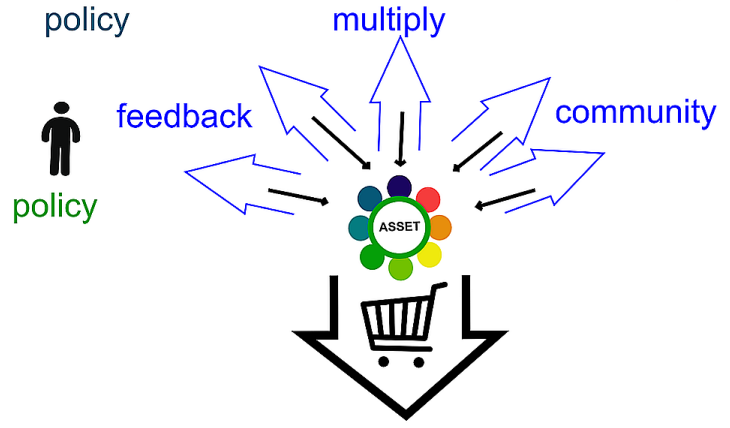

sustainable consumerism

We develop the ASSET pilot platform, which we implement at the moment. It is designed such that users follow their own modular self-determined policy, instead of a predefined one. In this way, they can express their individual concerns, for instance, prioritizing the purchase of products that meet organic production or animal welfare over the local origin of the products. At each purchase, consumers get a notion to which extent each product fits to their personally composed policy. Depending on the situation and premium, consumers decide to which extent they support their personally composed policy, see Figure 2 for illustration. This functionality facilitates the decision-making process and emphasizes the empowerment of consumers.

The ASSET pilot platform consists of three parts: (i) the ASSET smart phone application, (ii) the localization system at the supermarket, and (iii) the ASSET database system. The ASSET smart phone application acts as the personal user touch point of the ASSET pilot platform. Users provide input to the application that determines their political concerns and their preferences on various product and

Figure 2. Schematic presentation of the ASSET pilot platform from the individual perspective: a) A consumer states his personal policy in the ASSET application; b) Within the shop, the ASSET application informs the consumer about the related product properties (Klinglmayr, 2016)

a)

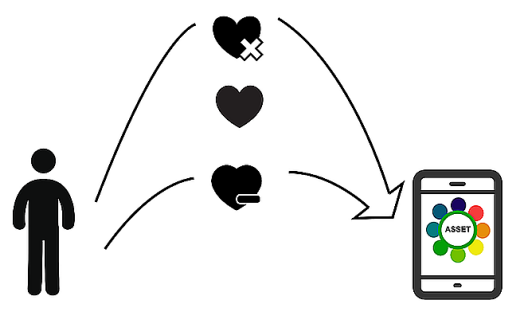

b)

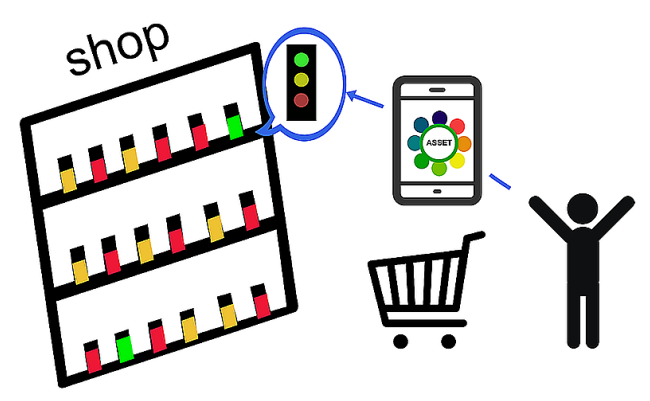


sustainability aspects, e.g. environment, quality, health, or social. This information is processed in the phone in a privacy-preserving way using techniques (Pournaras et al., 2016; Musciotto et al., 2016; Gentry, 2009) and mechanisms such as the nervousnet platform (Pournaras et al., 2015; Helbing \& Pournaras, 2015). The application informs the users on relevant product information, which assists users to choose the right products for them, according to their preferences. Additionally, the application links the user to social media platforms and contributes to the development of a community among users by providing feedback. Finally, the application allows a two-way interaction with the retailer.

The upcoming section "Smart Phone Localization" is dedicated to give a more detailed view on the localization system at the supermarket's shop floor.

The ASSET database system is the backbone of the ASSET pilot platform. It collects various kinds of product information from the database of the retailer, other open platforms, governmental databases and user forums. The aggregated data is frequently updated, characterized, classified and stored in the database.

\section{Social Dynamics}

Within the ASSET project, we generalize the above mentioned local organic network approach. We do so by enabling functionality that a local organic network has. We extend:

- The notion of communities to digital communities;

- The notion of "consumer next to me" to a consumer related to me;

- The physical location of a trusted market place to a combination of physical and virtual market place;

- The producers to retailers and production chains;

- The political focus of local and organic to individual concerns;

- The reduced, preselected product variety to broad supermarket varieties and finally;

- The local markets to global markets.

In order to provide similar functionality as in the local organic network, we employ the ASSET pilot platform to:

- Enable the creation of a relationship between retailer and consumer via the personal addressing;

- Enable the formation of trust between retailer and consumer via presenting product information for the consumer;

- Be able to follow one's own political concern;

- Being able to trust product qualities, via collected and processed product information from an independent institution;

- Maintaining an everyday shopping routine, by seamlessly integrating the product information;

- Create a community, and chat on the "market", by utilizing social media, interaction and feedback.

User integration and feedback will be acquired via field tests that will be used to analyze and evaluate the concept of the ASSET consumerism. The planned fields tests have the potential to show the increase of awareness among consumers, any changes and learning effects in consumers' behavior and attitude, the effectiveness of community building, and also self-interested values as indicated in e.g. (Yamoah et al., 2016). This field test is also interesting in the context of intention-behaviour gap in ethical consumption, see e.g. (Carrington et al., 2014; Hassan et al., 2016).

\section{Related Initiatives}

There are several initiatives that provide consumer guidance: comparison platforms, e.g. PhoneArena (phonearena.com) or Geizhals (geizhals.at), databases of product certifiers, e.g. Fairtrade International (fairtrade.net), smart phone applications on the phone, e.g. Buycott (buycott.com), Codecheck 
(codecheck.info), Map your Meal (mapyourmeal.org), personalizable product rankings on the web, e.g. Ethical Consumer (ethicalconsumer.org) and recommendation systems, e.g. Amazon (amazon. com), and contactless shopping experience, e.g. Amazon Go. All these initiatives provide valuable information for consumers, but at the same time face some shortcomings. Some do not cover all products in the store, are not available on the shop floor, or do not allow interactions among users or with the retailer. The ASSET platform is different, as its functionality guides right on the shop floor, and is integrated in the standard shopping routines. This aspect and consequence of spending additional time for the decision process is for example also addressed in (Schoolman, 2016). Consumers can interact with retailers, and the integration with the supermarket database allows updated information on all products.

\section{SMART PHONE LOCALIZATION}

To better understand the needs of the ASSET application, the shopping process is illustrated in the following. A typical consumer in a supermarket takes a trolley, passes through the entrance and walks in the supermarket. Some customers orientate themselves to find the first product of interest and walk aim-oriented towards the corresponding shelf. Other consumers simply walk along the corridors and stop if they register a product of interest. At the point in time, where the consumer stands in front of a particular shelf, the ASSET application is required to show the product information for the pertaining product selection. To do so, knowledge about the position of the smart phone within the shop must be available. Furthermore, if the orientation of the consumer is known, this can be beneficially used to display the products of interest.

The ASSET application requires a) the position - or if available - the pose (position and orientation) of the consumer, and b) the map of the market with the corresponding positions of the different product families. The indoor localization part a) is addressed in the following.

Performing indoor positioning of smart phones offers a wide variety of possible technical solutions. In this section, the ambient conditions usually existent in a market are stated and different technical solutions are evaluated under the given constraints.

\section{Ambient Conditions in a Market}

Depending on the positioning technology, different ambient conditions in the market are relevant. Most important for magnetic field-based and radio frequency (RF)-based techniques - detailed in section "Sensors, Actuators, and Localization Techniques" - is the presence of static and moving metallic objects as shelves, goods, or shopping trolleys and pallet trucks. Regarding visual/optical technologies, the fact of the presence of artificial light sources is important. The authors noticed that in some markets, background music or acoustic information is played/provided, which is an important condition in the case of acoustic techniques. Furthermore, data traffic over a wireless local area network (WLAN) or via different mobile phone standards is performed.

\section{Technical Requirements for Positioning}

Major hard requirements for a technical implementation are to minimize health risks. An epileptic seizure may be induced in case of high-frequent light pulses beyond the critical flicker frequency of approximately $100 \mathrm{~Hz}$. Also, people supported by a cardiac stimulator must not be exposed to a time-varying magnetic field. As a matter of course, several power and frequency band limitations regulated by law must be met.

The other requirements concern proper functioning on the smart phone. This addresses in-time positioning (instantaneous data processing) and an achievable positioning accuracy of approximately $3 \mathrm{~m}$ in order to determine the correct product family for the application. 
Additionally, the localization system is designed to optimize the following:

- A high localization accuracy - even in situations, where positioning is difficult, e.g., when the smart phone is placed inside a pocket, a bag, or inside the shopping trolley;

- Low energy consumption of the ASSET smartphone application and low processing time (mainly touching the positioning routine);

- Low initial (when starting the ASSET smart phone application) and continuous data traffic;

- Low memory requirements;

- Low continuous technical maintenance as changing batteries, re-calibration of fingerprint map, etc.;

- Little extra infrastructure in the shop and if so, the ability to easily rearrange shelves without need of reinstallation of infrastructure (i.e. no wired infrastructure on the shelves);

- Low energy demand of any extra hardware/infrastructure installed in the market;

- Low development costs and running costs;

- Low inconvenience for the consumer.

A proper trade-off between these optimization criteria must be found.

\section{Sensors, Actuators, and Localization Techniques}

Initially, technical solutions using extra hardware directly connected to the smart phone have also been considered. Examples include the use of (visual) odometry on a shopping trolley (Gai et al., 2014) and radio detection and ranging (radar), especially ultra-wideband (UWB) radar and radio frequency identification (RFID) protocols (Gezici \& Poor, 2009; Soganci et al., 2011; Hammer et al., 2016) or at DecaWave (http://www.decawave.com). But these techniques dropped out at an early stage in the technology decision process for reasons of high costs and inconveniences, since a physical or wireless connection between positioning hardware and smart phone must be established and power supply of the positioning hardware must be ensured.

The researchers assume that the following sensors, actuators, and protocols are available on a typical smart phone:

- An inertial measurement unit (IMU) including a 3-axis accelerometer, a 3-axis gyroscope, and a 3-axis magnetometer;

- An acoustic sensor (microphone) also working in the ultrasonic frequency band;

- An image sensor (camera, which is readable line-wise in order to enable fast readout and thus, to detect high frequent light pulses up to $1 \mathrm{kHz}$, c.f. (Aoyama and Oshima, 2015));

- An illumination sensor (only feasible for low frequencies e.g. to detect the exposure of the smart phone);

- A speaker, which also acts as ultrasonic transmitter;

- A light emitting diode (LED) (inconvenient or useless if actuator is not visible);

- A WLAN adapter;

- The Bluetooth low energy (BLE) protocol (one-way and two-way (pairing) communication);

- Various mobile phone standard protocols (e.g. global system for mobile communications (GSM), universal mobile telecommunication system (UMTS), long term evolution (LTE), etc.);

- The near field communication (NFC) protocol (Want, 2011).

On basis of the available utilities for localization stated above, a vast number of suitable positioning techniques can be deduced. This quantity of potential solutions is classified into the following technology groups.

By means of image processing performed on the smart phone, an absolute position can be obtained. Exemplary techniques are the well-known bar code or quick response (QR)-code, identifying a reference pattern on the floor, the image recognition of products by means of so-called planograms, 
cf. (Rivera-Rubio et al., 2014), or the transmission of coded light pulses above the critical flicker frequency of approximately $100 \mathrm{~Hz}$. Using visual odometry, which correlates sequential images taken by the smart phone, a relative position estimate can be obtained without any knowledge of the environment, see (Shangguan et al., 2014). Anyhow, in case of rotations, the localization accuracy decreases rapidly, cf. (Engel et al., 2013). Image processing performed on external hardware for visual smart phone detection, or visual customer tracking, suffer from the fact that the link to the correct smart phone must be established in an extra step.

Acoustic techniques including ultrasonic technologies as presented in (Murata et al., 2014) and (Liu et al., 2015) have the advantage of extremely low variances of the position estimates due to the low propagation velocity of acoustic waves in air. In the audible frequency band, low power signals must be used to avoid inconveniences, e.g., some kind of background music modulation. Regarding the ultrasonic frequency band, health issues might be possible (Leighton, 2016).

RF-waves penetrate nearly all materials except metal, but suffer from fading due to multipath wave propagation. The simplest RF-based technique is to evaluate the received signal strength indicator (RSSI) values of multiple anchor nodes with known positions and identifications (IDs). This technique only requires one-way communication and can be performed using WLAN and BLE, respectively. Proximity-related techniques as NFC suffer from extremely short range $(<0.5 \mathrm{~m})$ for read-out (Brown et al., 2013). More accurate localization techniques as time of arrival (ToA) or time difference of arrival (TDoA) demand anchor nodes synchronized in time, see (Vossiek et al., 2003). This synchronization procedure claims extra effort in hardware and energy. At least, angle of arrival (AoA) techniques require multiple antennas per anchor node. This technique is more accurate, compare to (Kotaru et al., 2015), but also more cost-intensive and time-consuming than an RSSIbased approach. All techniques requiring a backward channel need more power than is the case in one-way communication, since the different devices must transmit and receive or switch between these modes, respectively.

Positioning via GSM or other mobile phone standards as UMTS, LTE, etc. are known for their low accuracy. The achievable accuracy depends on the topography of the mobile network. Typical position errors are in the range of $20 \mathrm{~m}$ to $50 \mathrm{~m}$ or above, (Ibrahim and Youssef, 2012; Rydén et al., 2015).

All kinds of fingerprinting rely on tracking algorithms with knowing the distribution of, e.g., the earth's magnetic field as described in (Haverinen and Kemppainen, 2009) and (Haverinen, 2016), an artificial magnetic field, or the RSSI values of WLAN/BLE beacons as performed in (Faragher and Harle, 2015). Indoor measurements have shown that the geomagnetic field as well as the distribution of RSSI values of RF signals depends strongly on the presence of surrounding objects. Any rearrangement of objects requires a recalibration procedure, which is very time-consuming. One solution would be to use so called crowd-sourced techniques which uses the measurement data from a lot of users to generate a map of fingerprints of the physical measured values (Yang et al., 2013) and (Rai et al., 2012). However, this technique provides no or inaccurate localization results for the first users, because no reference data is available.

Dead reckoning using the IMU needs an additional stabilization technique (at least knowledge about the map of the shop) since the acceleration data must be integrated twice to achieve a relative position estimate. To investigate an existing solution, see (Bakshi \& Heshmati, 2015) and (Kang \& Han, 2015).

\section{Decision-Making of the Localization Strategy}

In this section, the pros and cons of the technology groups deduced above are derived. Finally, the choice of the technology is discussed and justified.

Several solutions require that the localization of the smart phone is done by an extra hardware covering multiple users. The link of the estimated position to the correct smartphone must be established, which is error-prone and challenging if people situate themselves within low distance. This holds, if the smart phone is an actuator, if passive (e.g. visual) smartphone detection is performed, or 
if the customer's position is estimated using a pressure sensitive foil. A first estimate of the achievable positioning accuracy and reasons of privacy suggest avoiding these localization technologies. I.e., ideally, positioning is performed on the smart phone directly. Alternatively, the demanded link is given using the Media-Access-Control (MAC) addresses of the devices.

Visual localization techniques require the corresponding actuators and sensors to be exposed. If a tracking algorithm is performed, this exposure must persist the whole localization time. Furthermore, continuous utilization of the image sensor encompasses high energy consumption. This is the case in short encoded light pulses for position estimation. Thus, for the current consideration, only those visual techniques remain, which provide a quick and absolute position estimate without any history as the bar code, or the QR code. Since this solution requires an interaction of the ASSET application user, it will only be used as fallback solution.

All kinds of fingerprinting suffer from the fact that the recorded data heavily depend on the orientation of the smartphone with respect to the global coordinate system. This is due to antennas' beam patterns which are not isotropic (Salhi et al., 2016). Even using data of the magnetic field sensor, which delivers a three-dimensional data vector of the magnetic flux densities, depend on the orientation because the housing of the sensors and neighbored components are not comparable in all directions. The distortion of the magnetic field in indoor environment is so immense that even a compass is ineffective to determine the magnetic north. Due to the time-consuming necessary recalibration process in objects rearrangement, all kinds of fingerprinting drop out.

GSM or similar positioning techniques via mobile phone standards are out of the question due to their low positioning accuracy. Acoustic technologies drop out in the decision process for reasons of inconveniences for the consumer and/or low available power, and health issues regarding the ultrasonic frequency band, respectively.

Dead reckoning using the IMU in combination with BLE beacons with an RSSI based approach (one-way communication) offers various advantages, cf. (Chen et al., 2015). Positioning using BLE beacons involves a comparably low demand in energy consumption and guarantees flexible rearrangement of the shelves (although the beacon positions must be updated). Using the IMU, the local accuracy can be augmented. Altogether, this combination matches most of the optimization criteria stated above and is, thus, chosen by the researchers.

In addition, a questionnaire was prepared by the researchers of the LCM GmbH and has been completed by the other ASSET project partners in order to have insights about the retailer's point of view of the best technology solution. The result of the questionnaire confirms to the researchers' choice.

\section{Measurements and Mathematical Background}

Naturally, the RSSI value decreases rapidly with increasing distance to the RF source due to the spherical propagation of the RF wave in free space. In indoor environment, waves propagate differently, depending on the construction of building materials and surrounding objects. In general, the attenuation for RF wave propagation is modeled in a so-called path loss model:

$$
P_{R X, d B m}=P_{T X, d B m}-L_{0}-10 c_{p} \log _{10}\left(\frac{r}{r_{0}}\right)
$$

where $P_{\mathrm{RX}, \mathrm{dBm}}$ denotes the receive (RX) power in $\mathrm{dBm}, P_{\mathrm{TX}, \mathrm{dBm}}$ the transmit (TX) power in $\mathrm{dBm}, L_{0}$ a constant offset in $\mathrm{dB}$, and $\mathrm{c}_{\mathrm{p}}$ a constant describing the scattering properties of the indoor environment (typically, $1.5 \leq \mathrm{c}_{\mathrm{p}} \leq 2$ ). The variable $r$ denotes the distance from the RF source in meters and $\mathrm{r}_{0}$ is chosen as $1 \mathrm{~m}$. The path loss model defines the attenuation of the RF wave due to the distance, but does not incorporate any losses due to multipath wave propagation (i.e. destructive interference). 
Figure 3 shows recorded RSSI data in relation to the distance $r$. Due to the multipath wave propagation, the variance of the RSSI data decreases with increasing distance. This is totally in contrary to common problems, where the variance increases with increasing distance. The parameters $L_{0}$ and $\mathrm{c}_{\mathrm{p}}$ describing the path loss model can be (re-)estimated adaptively based on the current position estimate, using the estimated distances to the BLE beacons. Estimating both parameters can cause problems if only few RSSI data for small distances are available. Generally, estimating only the offset $L_{0}$ is sufficient for this application.

Since not only the current position, but also the orientations of the smartphone and the consumer are of interest in the ASSET application (to be able to show only products in front of the consumer), and to decrease the variance of the position estimate, IMU data are added. By processing the gyroscope data, the relative orientation of the smart phone can be estimated. Unfortunately, the orientation of the consumer does not necessarily match with the smart phone's orientation (i.e., the smart phone may be rotated by the consumer).

In Figure 4, the short-time fast Fourier transform (FFT) of the $x$-component (walking direction) of the accelerometer data and the corresponding gyroscope data in $z$-direction are shown. The gyroscope data show positive values, if a counter-clockwise rotation is performed, and negative values for clockwise rotations, since the smart phone was held horizontally with the $z$-axis pointing up. Performing a short-time FFT allows to estimate the step frequency of about $1.5 \mathrm{~Hz}$, which is dominant in walking direction only. As a consequence, the orientation of the smart phone coordinate system is estimated to equal the pedestrian coordinate system. If a rotation without walking is performed, the step frequency cannot be determined. Re-estimating the orientation of the smartphone with respect to the consumer is possible again after at least 2 seconds of walking.

The information about the step frequency can also be used for velocity estimation. For this purpose, the step width (usually in a range between $0.5 \mathrm{~m}$ and $1 \mathrm{~m}$ ) must be continuously estimated. These calculations deliver essential bounds for estimating the velocity vector using the BLE based positioning algorithm.

Regarding BLE positioning, a preliminary evaluation of the achievable accuracy has been carried out. The measurement location was the archive of the library at the Johannes Kepler University Linz, Austria, where an area of approximately $450 \mathrm{~m}^{2}$ was chosen. Within this area, a total number of $60 \mathrm{BLE}$

Figure 3. iBKS beacon RSSI data and estimated path loss models (PLMs) estimating both parameters $\mathrm{L}_{0}$ and $c_{p}$ (solid line), estimating only $c_{p}$ with constant $L_{0}=60 \mathrm{~dB}$ (dash-pointed line), and estimating only $L_{0}$ with constant $c_{p}=1.8$ (dashed line)

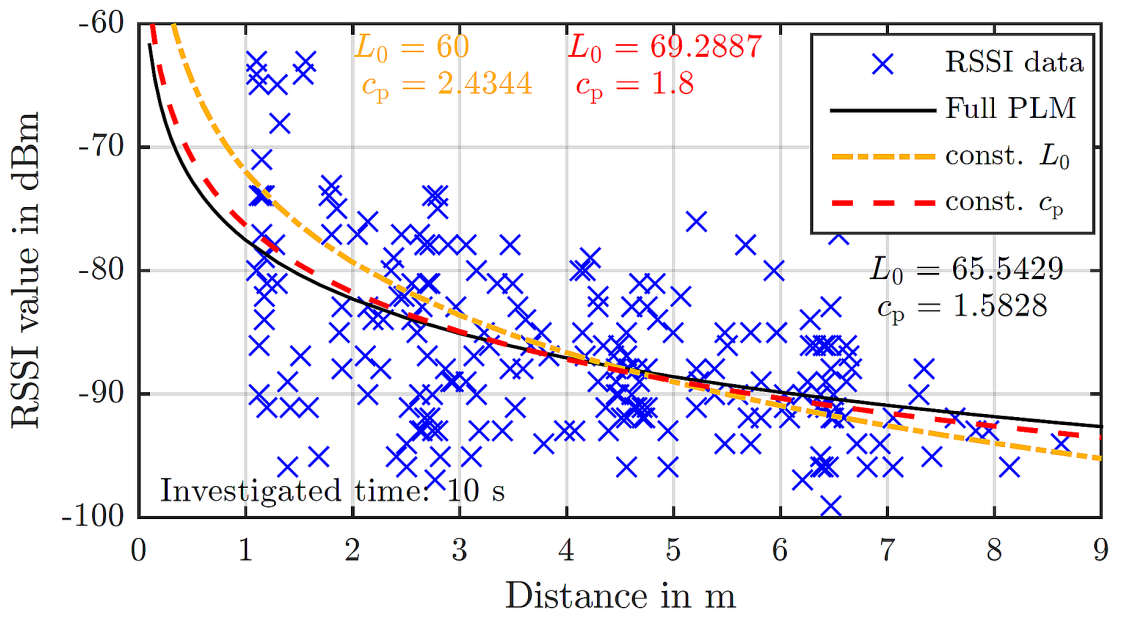


Figure 4. Normalized spectrogram of the x-component of the accelerometer data (component in walking direction) and corresponding gyroscope data. The black and white dash-pointed lines indicate times of rotation. Every second rotation is performed without walking.
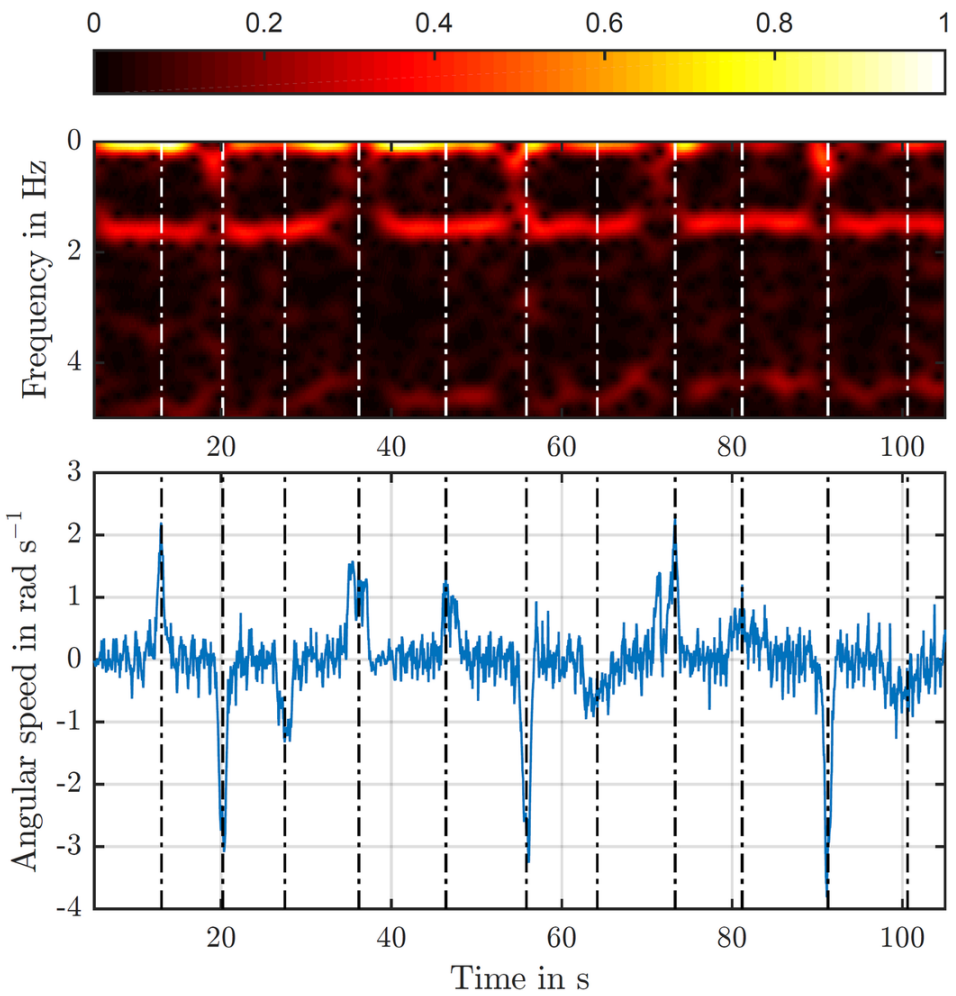

beacons were distributed with an average distance of $3.5 \mathrm{~m}$ to $4 \mathrm{~m}$. A top view of the measurement scenario can be seen in Figure 5. In order to be able to calculate the corresponding error statistics, marker positions with the corresponding time stamps are recorded approximately every $2 \mathrm{~m}$ during the measurements. The reference trajectory is obtained by an interpolation of the marker positions.

Various measurements were recorded along different trajectories, with different walking velocities, and different walking velocity profiles over time. Additionally, the persons participating in the measurements as well as the smart phones are varied.

Refer to Figure 6 . Over $90 \%$ of the position estimates provide an absolute error of less than $2 \mathrm{~m}$. Nearly $99 \%$ of the position estimates have an error of 3 m or less, which is a satisfying result, since the evaluation is purely based on BLE RSSI data. Additionally, taking the IMU data into account, the accuracy can be further improved.

Summing up, the chosen positioning solution is accurate enough for the current application of indoor positioning in a supermarket.

\section{Evaluating Self-Regulation within Consumers}

We demonstrate how the ASSET pilot platform enables collective awareness, harnesses network effects and contributes to sustainable consumption. In future field tests, we will demonstrate how consumers who employ the ASSET pilot platform evolve the ASSET consumerism towards collective awareness among consumers and retailers/producers. 
Figure 5. Top view of 3D laser scan of the measurement scenario with reference trajectory and estimated trajectory exemplarily displayed

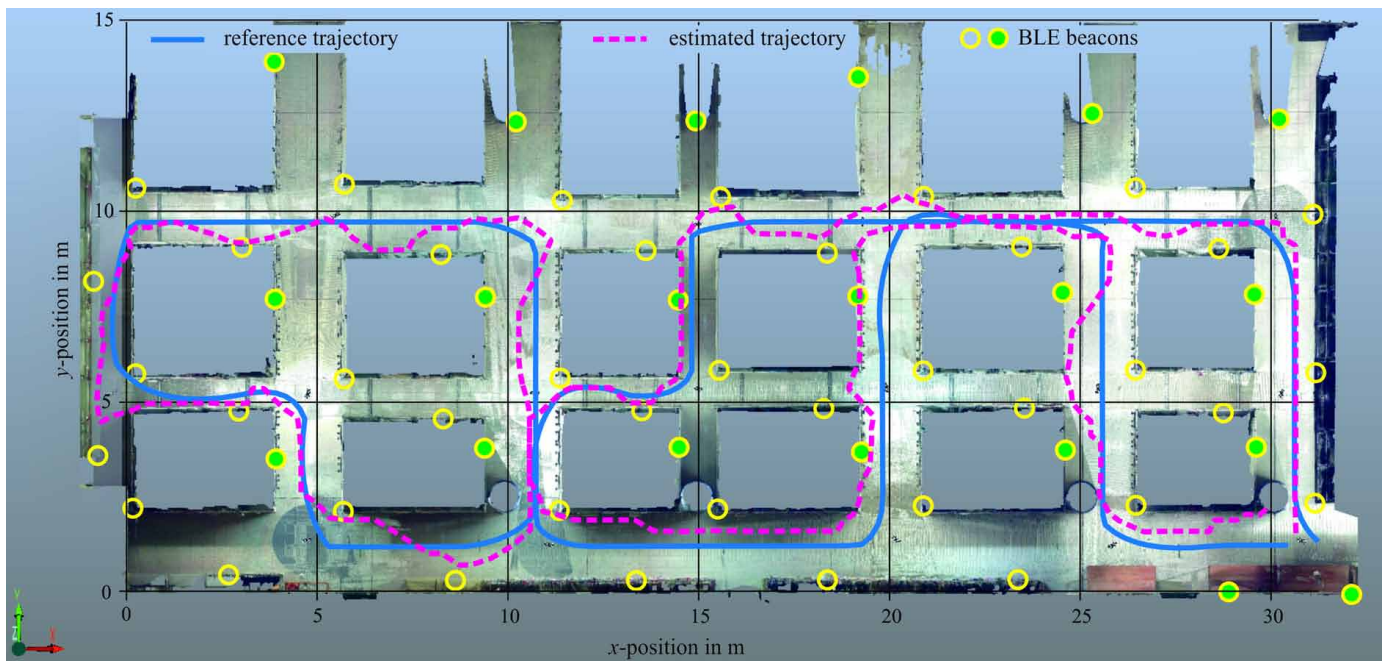

Figure 6. Cumulative error distribution function of all measured trajectories. The solid line indicates the error statistics for realtime positioning, which is the relevant case for the user of the ASSET smart phone application. If positioning is performed after data recording, the error statistics can still be improved (dashed line).

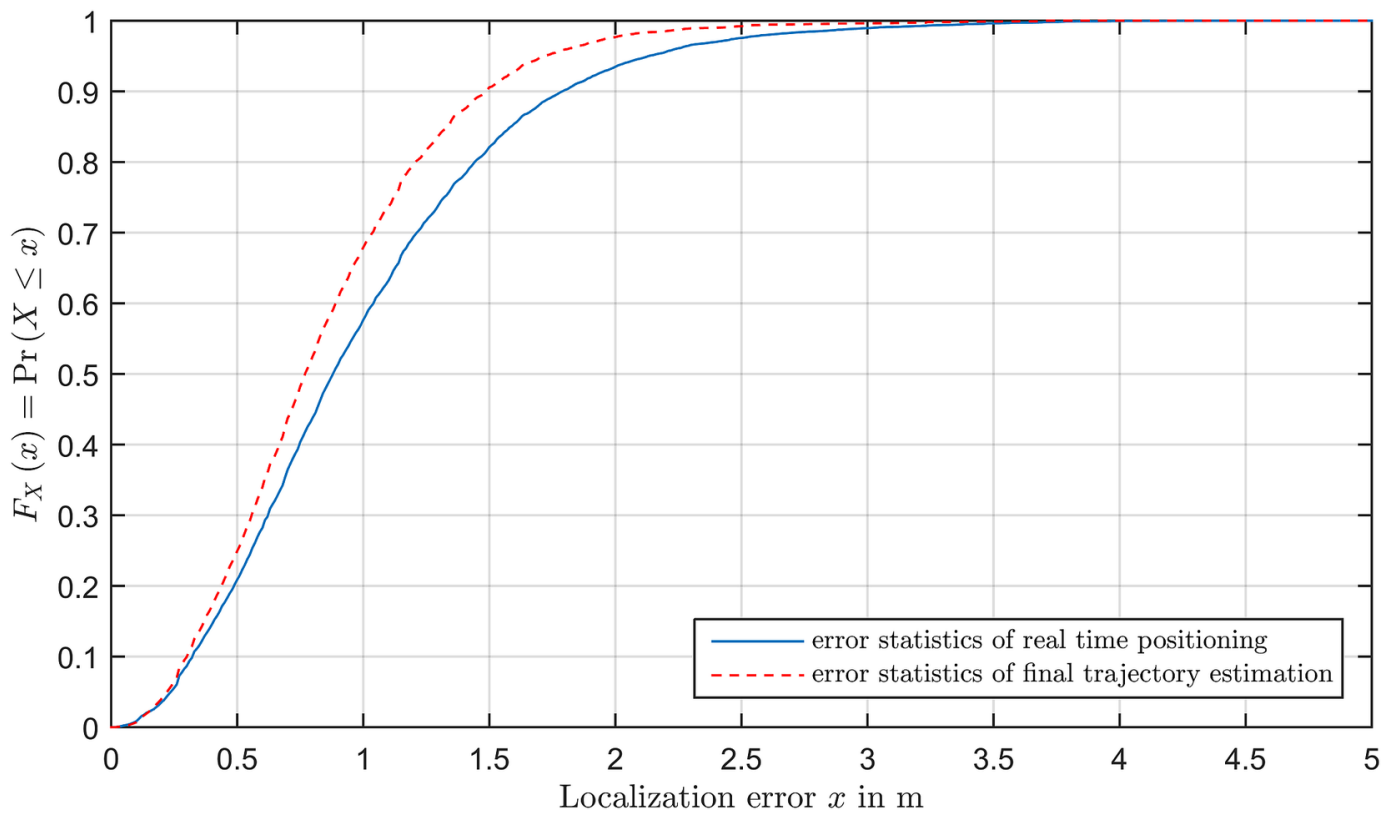

Regarding the future field tests, the ASSET pilot platform will be implemented in two supermarkets. Due to significant differences in citizen attitudes within Europe, we have chosen supermarkets in different countries (Estonia and Spain) to have a better representation of the average citizen. 
The implementation will include the following actions:

- Mounting of the sensor network. We use Bluetooth beacons, which will be mounted on the shelves of the supermarket. We use the smart phone sensors, e.g. accelerometer and gyroscope, to improve the accuracy of the positioning;

- Establishment of a connection to the supermarket IT system. We implement a secure software interface to get up-to-date product information from the database of the retailer;

- $\quad$ Mounting of a WIFI;

- Development of the smart phone application. The application will be available on the Google application store;

- Attracting consumers. We encourage the general consumer to participate in the field tests. Especially for the second field test, we advertise the application in front of the store. We have personnel at the entrance who facilitate the participation process. One of our partners has a "living lab" facility with test-users, who are personally invited to join the test. Loyalty card users are addressed and invited to participate. We motivate the participation with remuneration after the field tests. Also, the ASSET platform itself provides instant gratification for its users by design. The hiring process will be performed systematically to prevent biases and to guarantee the integrity of the scientific results.

Two field test iterations are performed. The primary goal of the first test is to ensure proper functionality of the ASSET pilot platform. Additionally, we obtain valuable user feedback on platform properties. These include feedback on the user interfaces, the localization system, the product information system, the usability, the interaction with social media, and the seamless integration into the shopping routines. The feedback is evaluated and the platform is improved.

The user feedback is obtained via direct and indirect means. We encourage the consumers to provide feedback via questionnaires. The questionnaires concern the usability of the application. The indirect feedback addresses the way the application is used in the test scenarios.

The second field test lasts around three to four months, depending on the degree of integration and retailer policy restrictions. It focuses on the actions and interactions of the test users. We obtain direct and indirect feedback from users via feedback buttons, polls, the aggregation of usage patterns and social media data. Additionally, we obtain data on purchase changes of goods and direct feedback from the retailers. Via analyzing changes in usage patterns, purchase changes, social media data, and consumer dynamics, we demonstrate how the ASSET consumerism changes the decision-making of the individual, raises collective awareness and contributes to sustainability.

With this aggregated user feedback, we focus on two aspects. First, we measure if and how the individual decision-making changes. We expect to get valuable insights by analyzing changes in the preference settings of consumers, and the answers to dedicated poll questions. Second, we study, if the awareness among consumers on their collective purchasing power increases. We also study our claim, that consumers contribute to sustainability because they have objective support in their decision-making process.

\section{CONCLUSION AND OUTLOOK}

With the introduction of the ASSET pilot platform we face the "one policy fits all" problem of political consumerism. We give the consumers the ability to follow their own policies when purchasing, by providing objective and tailored product information. The outlined position estimation process allows a simple integration into a consumer's shopping routine and provides additional information about only a few product sections. We focus on the grocery products in the shopping process of supermarkets. 
With this concept, we build upon the intrinsic motivation of the individual consumer and at the same time facilitate self-regulation among consumers towards a sustainable consumerism. Based on our findings we expect to extend our research to more general decision support systems.

\section{ACKNOWLEDGMENT}

This project has received funding from the European Union's Horizon 2020 research and innovation programme under grant agreement No 688364 and by Linz Center of Mechatronics (LCM) in the framework of COMET-K2. This article reflects only the author's view and the Commission is not responsible for any use that may be made of the information it contains. 


\section{REFERENCES}

Adams, M., \& Raisborough, J. (2010). Making a difference: Ethical consumption and the everyday. The British Journal of Sociology, 61(2), 256-274. doi:10.1111/j.1468-4446.2010.01312.x PMID:20579054

Andersen, A. H. (2011). Organic food and the plural moralities of food provisioning. [Subjecting the Objective Participation, Sustainability and Agroecological Research.]. Journal of Rural Studies, 27(4), 440-450. doi:10.1016/j.jrurstud.2011.07.004

Andorfer, V. A., \& Liebe, U. (2013). Consumer behavior in moral markets. on the relevance of identity, justice beliefs, social norms, status, and trust in ethical consumption. European Sociological Review, 29(6), 1251-1265. doi:10.1093/esr/jct014

Aoyama, H., \& Oshima, M. (2015). Visible light communication using a conventional image sensor. In Proceedings of the 2015 12th Annual IEEE Consumer Communications and Networking Conference (CCNC) (pp. 103-108). doi:10.1109/CCNC.2015.7157954

Bakshi, R. \& Heshmati, A. (2015). Method and system for automatically generating location signatures for positioning using inertial sensors. Patent: EP 2878924 A1.

Balsiger, P. (2013). Embedding political consumerism: A conceptual critique. European University Institute.

Brown, T. W. C., Diakos, T., \& Briffa, J. A. (2013). Evaluating the eavesdropping range of varying magnetic field strengths in NFC standards. In Proceedings of the 2013 7th European Conference on Antennas and Propagation $(E u C A P)$ (pp. 3525-3528).

Carrington, M. J., Neville, B. A., \& Whitwell, G. J. (2014). Lost in translation: Exploring the ethical consumer intention behavior gap. Journal of Business Research, 67(1), 2759-2767. doi:10.1016/j.jbusres.2012.09.022

Chen, Z., Zhu, Q., Jiang, H., \& Soh, Y. C. (2015). Indoor localization using smartphone sensors and ibeacons. In Proceedings of the 2015 IEEE 10th Conference on Industrial Electronics and Applications (ICIEA) (pp. 1723-1728). doi:10.1109/ICIEA.2015.7334389

Dobson, A. (2003). Citizenship and the Environment. Oxford University. doi:10.1093/0199258449.001.0001

Engel, J., Sturm, J., \& Cremers, D. (2013). Semi-dense visual odometry for a monocular camera. In Proceedings of the 2013 IEEE International Conference on Computer Vision (ICCV) (pp. 1449-1456). doi:10.1109/ICCV.2013.183

European Commission. (2011). Commission staff working paper, consumer empowerment in the eu. Commission staff working paper, sec 469 final.

Faragher, R., \& Harle, R. (2015). Location fingerprinting with Bluetooth low energy beacons. IEEE Journal on Selected Areas in Communications, 33(11), 2418-2428. doi:10.1109/JSAC.2015.2430281

Ferrara, E. (2015). Manipulation and abuse on social media by Emilio Ferrara with Ching-Man Au Yeung as coordinator. ACM SIGWEB Newsletter, Spring(1), 4.

Gai, S., Jung, E. J., \& Yi, B. J. (2014). Localization algorithm based on zigbee wireless sensor network with application to an active shopping cart. In Proceedings of the 2014 IEEE/RSJ International Conference on Intelligent Robots and Systems (pp. 4571-4576). doi:10.1109/IROS.2014.6943210

Gentry, C. (2009). A fully homomorphic encryption scheme [PhD thesis]. Stanford University.

Gezici, S., \& Poor, H. V. (2009). Position estimation via ultra-wide-band signals. Proceedings of the IEEE, 97(2), 386-403. doi:10.1109/JPROC.2008.2008840

Ghvanidze, S., Velikova, N., Dodd, T. H., \& Oldewage-Theron, W. (2016). Consumers environmental and ethical consciousness and the use of the related food products information: The role of perceived consumer effectiveness. Appetite, 107, 311-322. doi:10.1016/j.appet.2016.08.097 PMID:27554182

Gjerris, M., Gamborg, C., \& Saxe, H. (2016). What to buy? on the complexity of being a critical consumer. Journal of Agricultural \& Environmental Ethics, 29(1), 81-102. doi:10.1007/s10806-015-9591-6

Grauel, J. (2016). Being authentic or being responsible? food consumption, morality and the presentation of self. Journal of Consumer Culture, 16(3), 852-869. doi:10.1177/1469540514541880 
Gunitsky, S. (2015). Corrupting the cyber-commons: Social media as a tool of autocratic stability. Perspectives on Politics, 13(01), 42-54. doi:10.1017/S1537592714003120

Hammer, F., Yudanto, R., Neumann, K., Pichler, M., Cockx, J., Niestroj, C., \& Petré, F. (2016). Performance evaluation of 3d-position estimation systems. IEEE Sensors Journal, 16(16), 6416-6424. doi:10.1109/ JSEN.2016.2581489

Hassan, L. M., Shiu, E., \& Shaw, D. (2016). Who says there is an intention-behaviour gap? assessing the empirical evidence of an intention-behaviour gap in ethical consumption. Journal of Business Ethics, 136(2), 219-236. doi:10.1007/s10551-014-2440-0

Haverinen, J. (2016). Indoor magnetic field based localization discovery. Patent: US 2016/0003625 A1.

Haverinen, J., \& Kemppainen, A. (2009). Global indoor self-localization based on the ambient magnetic field. Robotics and Autonomous Systems, 57(10), 1028-1035. doi:10.1016/j.robot.2009.07.018

Helbing, D., \& Pournaras, E. (2015). Society: Build digital democracy. Nature, 527(7576), 33-34. doi:10.1038/527033a PMID:26536943

Ibrahim, M., \& Youssef, M. (2012). Cellsense: An accurate energy-efficient gsm positioning system. IEEE Transactions on Vehicular Technology, 61(1), 286-296. doi:10.1109/TVT.2011.2173771

Ipsos and London Economics Consortium. (2013). Consumer market study on the functioning of voluntary food labelling schemes for consumers in the european union. Eahc/fwc/2012 86 04. European Commission.

Kang, W., \& Han, Y. (2015). Smartpdr: Smartphone-based pedestrian dead reckoning for indoor localization. IEEE Sensors Journal, 15(5), 2906-2916. doi:10.1109/JSEN.2014.2382568

Klinglmayr, J. (2016). ASSET factsheet. Retrieved February 09, 2017 from http://www. asset-consumerism.eu

Klinglmayr, J., Bergmair, B., \& Pournaras, E. (2016). Sustainable consumerism via self-regulation. In Proceedings of the 2016 IEEE 1st International Workshops on Foundations and Applications of Self* Systems (FAS*W) (pp. 138-142). doi:10.1109/FAS-W.2016.40

Kotaru, M., Joshi, K., Bharadia, D., \& Katti, S. (2015). SpotFi: Decimeter Level Localization Using WiFi. SIGCOMM. Computer Communication Review, 45(4), 269-282. doi:10.1145/2829988.2787487

Leighton, T. G. (2016). Are some people suffering as a result of increasing mass exposure of the public to ultrasound in air? Proceedings of the Royal Society of London A: Mathematical, Physical and Engineering Sciences, 472(2185). doi:10.1098/rspa.2015.0624

Liu, K., Liu, X., and Li, X. (2015). Guoguo: Enabling fine-grained smartphone localization via acoustic anchors. IEEE Transactions on Mobile Computing, 15(5), 1144-1156.

Micheletti, M. (2003). Political virtue and shopping: individuals, consumerism, and collective action. Palgrave Macmillan, US. doi:10.1057/9781403973764

Micheletti, M., Stolle, D., \& Follesdal, A. (2003). Politics, Products, and Markets: Exploring Political Consumerism Past and Present. NJ: Transaction Publishers.

Murata, S., Yara, C., Kaneta, K., Ioroi, S., \& Tanaka, H. (2014). Accurate indoor positioning system using near-ultrasonic sound from a smartphone. In Proceedings of the 2014 Eighth International Conference on Next Generation Mobile Apps, Services and Technologies (NGMAST) (pp. 13-18). doi:10.1109/NGMAST.2014.17

Musciotto, F., Delpriori, S., Castagno, P., \& Pournaras, E. (2016). Mining social interactions in privacy-preserving temporal networks. In Proceedings of the 2nd International Workshop on Dynamics in Networks-DyNo 2016. IEEE. doi:10.1109/ASONAM.2016.7752378

Organisation for Economic Co-operation and Development (2001). Policies to promote sustainable consumption: An overview. ENV/EPOC/WPNEP, 18.

Pournaras, E., Moise, I., \& Helbing, D. (2015). Privacy preserving ubiquitous social mining via modular and compositional virtual sensors. In Proceedings of the 2015 IEEE 29th International Conference on Advanced Information Networking and Applications (pp. 332-338). IEEE. doi:10.1109/AINA.2015.203 
Pournaras, E., Nikolic, J., Velásquez, P., Trovati, M., Bessis, N., \& Helbing, D. (2016). Self-regulatory information sharing in participatory social sensing. EPJ Data Science, 5(1), 1. doi:10.1140/epjds/s13688-016-0074-4

Rai, A., Chintalapudi, K. K., Padmanabhan, V. N., \& Sen, R. 2012. Zee: zero-effort crowdsourcing for indoor localization. In Proceedings of the 18th annual international conference on Mobile computing and networking (Mobicom '12) (pp. 293-304).

Rivera-Rubio, J., Idrees, S., Alexiou, I., Hadjilucas, L., \& Bharath, A. A. (2014). A dataset for hand-held object recognition. In Proceedings of the 2014 IEEE International Conference on Image Processing (ICIP) (pp. 5881-5885).

Rydén, H., Razavi, S. M., Gunnarsson, F., Kim, S. M., Wang, M., Blankenship, Y., Grövlen, A., \& Busin, Å. (2015). Baseline performance of LTE positioning in 3gpp 3d mimo indoor user scenarios. In 2015 International Conference on Location and GNSS (ICL-GNSS) (pp. 1-6).

Salhi, M. A., en, O., Çakr, S., and Çetinta, M. (2016). 3d/2d radiation pattern measurement of different gsm phones for emc applications. In Proceedings of the 2016 International Symposium on Electromagnetic Compatibility EMC EUROPE (pp. 695-700). doi:10.1109/EMCEurope.2016.7739219

Schoolman, E. D. (2016). Completing the circuit: Routine, reflection, and ethical consumption. Sociological Forum, 31(3), 619-641. doi:10.1111/socf.12266

Seyfang, G. (2006). Ecological citizenship and sustainable consumption: Examining local organic food networks. Journal of Rural Studies, 22(4), 383-395. doi:10.1016/j.jrurstud.2006.01.003

Shangguan, L., Zhou, Z., Yang, Z., Liu, K., Li, Z., Zhao, X., \& Liu, Y. (2014). Towards accurate object localization with smartphones. IEEE Transactions on Parallel and Distributed Systems, 25(10), 2731-2742. doi:10.1109/ TPDS.2013.236

Soganci, H., Gezici, S., \& Poor, H. V. (2011). Accurate positioning in ultra-wideband systems. IEEE Wireless Communications, 18(2), 19-27. doi:10.1109/MWC.2011.5751292

Stolle, D., Hooghe, M., \& Micheletti, M. (2005). Politics in the supermarket: Political consumerism as a form of political participation. International Political Science Review, 26(3), 245-269. doi:10.1177/0192512105053784

TNS Political \& Social. (2013). Attitudes of Europeans towards building the single market for green products. flash eurobarometer 367. Technical report. European Commission.

Vossiek, M., Wiebking, L., Gulden, P., Weighardt, J., \& Hoffmann, C. (2003). Wireless Local Positioning Concepts, Solutions, Applications. In Proceedings of the Radio and Wireless Conference, RAWCON '03 (pp. 219-224). doi:10.1109/RAWCON.2003.1227932

Want, R. (2011). Near field communication. IEEE Pervasive Computing / IEEE Computer Society [and] IEEE Communications Society, 10(3), 4-7. doi:10.1109/MPRV.2011.55

Witt, U. (1997). Self-organization and economics - what is new? Structural Change and Economic Dynamics, 8(4), 489-507. doi:10.1016/S0954-349X(97)00022-2

World Wide Fund For Nature. (2016). footprint calculator. Retrieved February 8, 2017 from http://footprint. wwf.org.uk

Yamoah, F. A., Duffy, R., Petrovici, D., \& Fearne, A. (2016). Towards a framework for understanding fairtrade purchase intention in the mainstream environment of supermarkets. Journal of Business Ethics, 136(1), 181-197. doi:10.1007/s10551-014-2509-9

Yang, S., Dessai, P., Verma, M., \& Gerla, M. (2013). FreeLoc: Calibration-free crowdsourced indoor localization. In Proceedings of the 2013 IEEE INFOCOM (pp. 2481-2489.

\section{ENDNOTE}

1 Section here can be compared with (Organisation for Economic Co-operation and Development, 2001) 
Johannes Klinglmayr received a Dipl.-Ing. degree in technical mathematics from the Technical University of Vienna, Vienna, Austria, in 2007, a M.A. degree in applied mathematics from the University of Michigan, Ann Arbor, USA, in 2008, and a Dr. techn. degree in information technology from the University of Klagenfurt, Klagenfurt, Austria, in 2013. He was with the University of Klagenfurt and Lakeside Labs, Klagenfurt, from 2008 to 2013. From 2009 to 2013, he was a repeating visiting researcher with the Max-Planck Institute for Dynamic and SelfOrganization, Gottingen, Germany. He is a Senior Engineer at the Linz Center of Mechatronics, Linz, since 2014. His research focus is on self-organization and interdisciplinary applications.

Bernhard Bergmair received his M.Sc. degree in technical physics from Vienna University of Technology (Austria) in 2008 and received his Sc.D. in engineering sciences in 2013. His research focuses on the interdependence of emerging technologies, society and corporate strategies. Research methods include open foresight processes involving interdisciplinary teams.

Maria Klaffenböck received a Dipl.Ing. (M.Sc.) and Dr. techn. (Ph.D.) degrees in mechatronics from Johannes Kepler University Linz, Austria, in 2005 and in 2014, respectively. She was a researcher with the Institute for Communications Engineering and RF-Systems (NTHFS), Johannes Kepler University Linz, from 2005 to 2014. Since 2015, she has been with the Linz Center of Mechatronics $\mathrm{GmbH}$. Her current research interests include cryptography, statistical signal processing, parameter estimation, indoor localization, and radar signal processing.

Leander B. Hörmann received his Dipl.-Ing. (equivalent to MSc.) in Telematics and his Dr.techn. in Electrical Engineering from Graz University of Technology, Austria, in 2010 and 2013, respectively. As senior engineer and software development coordinator at the Sensors \& Communication Area of the Linz Center of Mechatronics $\mathrm{GmbH}$, Austria, he conducts research and works on industry-oriented projects. His research interests include system architecture design, system modeling, sensor and communication networks, and co-simulation of software and hardware.

Evangelos Pournaras is a senior scientist in the Professorship of Computational Social Science, at ETH Zurich, Zurich, Switzerland. He was earlier at Delft University of Technology and VU University Amsterdam in the Netherlands, where he completed his PhD studies in 2013 with the thesis "Multi-level Reconfigurable Selforganization in Overlay Services". Since 2007, he holds a MSc with distinction in Internet Computing from University of Surrey, UK and since 2006 a BSc on Technology Education and Digital Systems from University of Piraeus, Greece. Evangelos has also been a visiting researcher at EPFL in Switzerland and has industry experience at IBM T.J. Watson Research Center in the USA. He serves the editorial board and the program committees of several international conferences and journals. He has several publications in high-impact journals and conferences in the area of distributed systems, including a best journal paper award. Smart Grids and social sensing/mining are some application domains of his expertise. Evangelos is currently working on the ASSET project, in which he builds a privacy-preserving and distributed product rating system for more sustainable supply-demand systems. 